\title{
Demographic, clinical, and service-use characteristics related to the clinician's recommendation to transition from child to adult mental health services
}

\author{
S. E. Gerritsen ${ }^{1}$ (1) - L. S. van Bodegom ${ }^{1,2}$. G. C. Dieleman ${ }^{1}$ - M. M. Overbeek ${ }^{2,3} \cdot$ F. C. Verhulst ${ }^{1,4} \cdot$ D. Wolke ${ }^{5}$. \\ D. Rizopoulos ${ }^{6} \cdot$ R. Appleton ${ }^{7}$. T. A. M. J. van Amelsvoort ${ }^{8,9}$. C. Bodier Rethore ${ }^{10}$. F. Bonnet-Brilhault ${ }^{10}$. I. Charvin ${ }^{11}$. \\ D. Da Fonseca ${ }^{11}$ - N. Davidović ${ }^{12,13} \cdot$ K. Dodig-Ćurković ${ }^{14,15,16} \cdot$ A. Ferrari ${ }^{17,18}$ - F. Fiori ${ }^{19,20,21} \cdot$ T. Franić $^{12,13}$. \\ C. Gatherer ${ }^{22}$ - G. de Girolamo ${ }^{17} \cdot$ N. Heaney ${ }^{19} \cdot$ G. Hendrickx ${ }^{23} \cdot$ R. Jardri ${ }^{24} \cdot$ A. Kolozsvari ${ }^{21} \cdot$ H. Lida-Pulik ${ }^{25}$. \\ K. Lievesley ${ }^{19}$ - J. Madan ${ }^{26} \cdot$ M. Mastroianni ${ }^{19,20}$ - V. Maurice ${ }^{27}$. F. McNicholas ${ }^{28,29} \cdot$ R. Nacinovich ${ }^{30,31} \cdot$ A. Parenti ${ }^{32}$. \\ M. Paul ${ }^{22,33} \cdot$ D. Purper-Ouakil ${ }^{27,34}$ - L. Rivolta ${ }^{35,36} \cdot$ V. de Roeck ${ }^{37,38} \cdot$ F. Russet $^{27} \cdot$ M. C. Saam $^{39} \cdot$ I. Sagar-Ouriaghli $^{19}$.

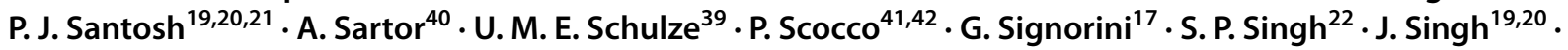

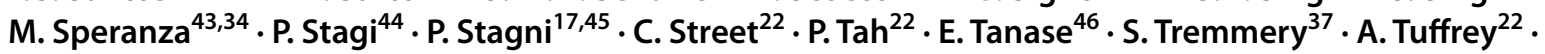 \\ H. Tuomainen ${ }^{22} \cdot$ L. Walker ${ }^{22} \cdot$ A. Wilson ${ }^{22} \cdot$ A. Maras ${ }^{1,2} \cdot$ for the Milestone Consortium
}

Received: 7 July 2021 / Accepted: 22 January 2022 / Published online: 10 February 2022

(c) The Author(s) 2022

\begin{abstract}
Purpose The service configuration with distinct child and adolescent mental health services (CAMHS) and adult mental health services (AMHS) may be a barrier to continuity of care. Because of a lack of transition policy, CAMHS clinicians have to decide whether and when a young person should transition to AMHS. This study describes which characteristics are associated with the clinicians' advice to continue treatment at AMHS.

Methods Demographic, family, clinical, treatment, and service-use characteristics of the MILESTONE cohort of 763 young people from 39 CAMHS in Europe were assessed using multi-informant and standardized assessment tools. Logistic mixed models were fitted to assess the relationship between these characteristics and clinicians' transition recommendations.

Results Young people with higher clinician-rated severity of psychopathology scores, with self- and parent-reported need for ongoing treatment, with lower everyday functional skills and without self-reported psychotic experiences were more likely to be recommended to continue treatment. Among those who had been recommended to continue treatment, young people who used psychotropic medication, who had been in CAMHS for more than a year, and for whom appropriate AMHS were available were more likely to be recommended to continue treatment at AMHS. Young people whose parents indicated a need for ongoing treatment were more likely to be recommended to stay in CAMHS.

Conclusion Although the decision regarding continuity of treatment was mostly determined by a small set of clinical characteristics, the recommendation to continue treatment at AMHS was mostly affected by service-use related characteristics, such as the availability of appropriate services.
\end{abstract}

Keywords Child and adolescent mental health services · Adult mental health services · Young adults · Transition

S. E. Gerritsen and L. S. van Bodegrom contributed equally as co-first authors

Members of the wider MILESTONE consortium are listed under the acknowledgments.

G. C. Dieleman

g.dieleman@erasmusmc.nl

Extended author information available on the last page of the article

\section{Introduction}

Mental health services for children and adolescents will usually provide care until the young person is aged $16-19$ years. Some argue that the provision of distinct child and adolescent mental health services (CAMHS) and adult mental health services (AMHS) may hamper the continuity of care $[1,2]$ and that this discontinuity may adversely affect the mental health of young people. Indeed, previous research 
indicates $30 \%$ to $84 \%$ of young people experience a discontinuity of care after reaching the upper age limit of their CAMHS [3-5], yet no studies to date have investigated how a discontinuity of care may affect the mental health of young people. Additionally, previous studies often do not clearly indicate whether or not the discontinuity of care is in accordance with the recommendation from the CAMHS clinician, i.e., that further mental health care was not required. To provide insight in reasons for this discontinuity, it is important to disentangle the different steps in the process of transition from CAMHS to AMHS.

Once young people reach the upper age limit of their CAMHS, clinicians need to advise patients and their parents about the type of care, if any, that will be needed going forwards to ensure optimal mental health. First, the clinicians' recommendations address any need for continued mental health care. Second, if continuation of mental health care is deemed necessary, the clinician needs to decide where such care should be provided. In certain circumstances, this might include continuing at CAMHS for a short period to conclude treatment, or alternatively, transfer to AMHS or to another type of mental health service. The clinician's recommendation regarding continuity of care is the first step in the process of transition and may have a significant impact on the young person's outcomes. Therefore, our study focusses on the clinician's transition recommendation and aims to describe which factors are associated with this recommendation.

Several studies have tested factors associated with referral to AMHS after adolescents reached the upper age limit of their mental health services. The results of these studies are consistent in showing that a clinical classification of a psychotic or personality disorder is associated with a greater likelihood of referral to adult mental health care [4, $6,7]$, but are inconclusive with regard to demographic and family characteristics and treatment and service-use related characteristics, specifically length of stay in CAMHS and psychotropic medication use $[4,6,7]$. Comparison of the results of existing studies is hampered by variations in methodology, such as whether bivariate or multivariate analyses are used, and variations in the groups that were compared: most studies compared young people who were referred or transitioned to AMHS to young people who did not [4, 5, 7]. Other studies described young people who were referred to AMHS or transitioned compared to those who were discharged [8] or those who stayed in CAMHS [9]. Other indicators of severity of psychopathology have not previously been studied in relation to referral such as the clinician's rating of severity of psychopathology, self- and parentreported problem levels, psychotic experiences, suicidality, daily functional skills, self- and parent-reported need for ongoing treatment, inpatient service use, and visits to the accident and emergency department.
This European study used multi-informant standardized assessment to determine which demographic, family, clinical, treatment, and service-use-related characteristics are associated with clinicians' transition recommendation to continue care in general, and the recommendation to continue care at AMHS specifically, using multivariate analyses.

\section{Methods}

\section{Study design and participants}

This study was carried out on the MILESTONE cohort [10, 11]. A total of 786 young people were recruited from 39 CAMHS in Europe (Belgium, Croatia, France, Germany, Ireland, Italy, The Netherlands, and The United Kingdom) between October 2015 and December 2016 (see Fig. 1). Eligible young people were receiving care in CAMHS and within a year of reaching the upper age limit of that CAMHS (or three months after, if still in CAMHS). A total of 6238 young people had a patient record at one of 39 CAMHS and met the age criterion. They were assessed further for eligibility and inclusion criteria by care coordinators and clinicians. A total of 2941 young people were considered ineligible, of which 220 young people no longer met the age criterion and 1424 no longer visited the CAMHS at the time they could be informed about the study. Care coordinators and clinicians introduced the study to 1692 young people, after which young people indicated whether they consented to being contacted by the research team. Due to medical ethical reasons, our research team was not allowed to contact young people to inform them about the study directly. Of all young people to whom the study was introduced $(n=1692), 763$ young people (45.1\%) were recruited to the MILESTONE cohort.

Country-specific consent procedures were followed, according to national laws and medical ethical regulations. A parent and a CAMHS clinician (a mental health professional responsible for, or coordinating, the care for the young person) were also asked to participate in the study. A total of 763 young people consented to participate and completed baseline assessments. Gerritsen et al. [11] provide a detailed description of the recruitment process and cohort characteristics. The study protocol was approved (ISRCTN83240263; NCT03013595) by the UK National Research Ethics Service Committee West Midlands-South Birmingham (15/ $\mathrm{WM} / 0052$ ) and ethics boards in participating countries.

\section{Procedure}

Baseline assessments were conducted after consent was provided. Young people and their parents completed interviews and questionnaires during assessments which took place at 


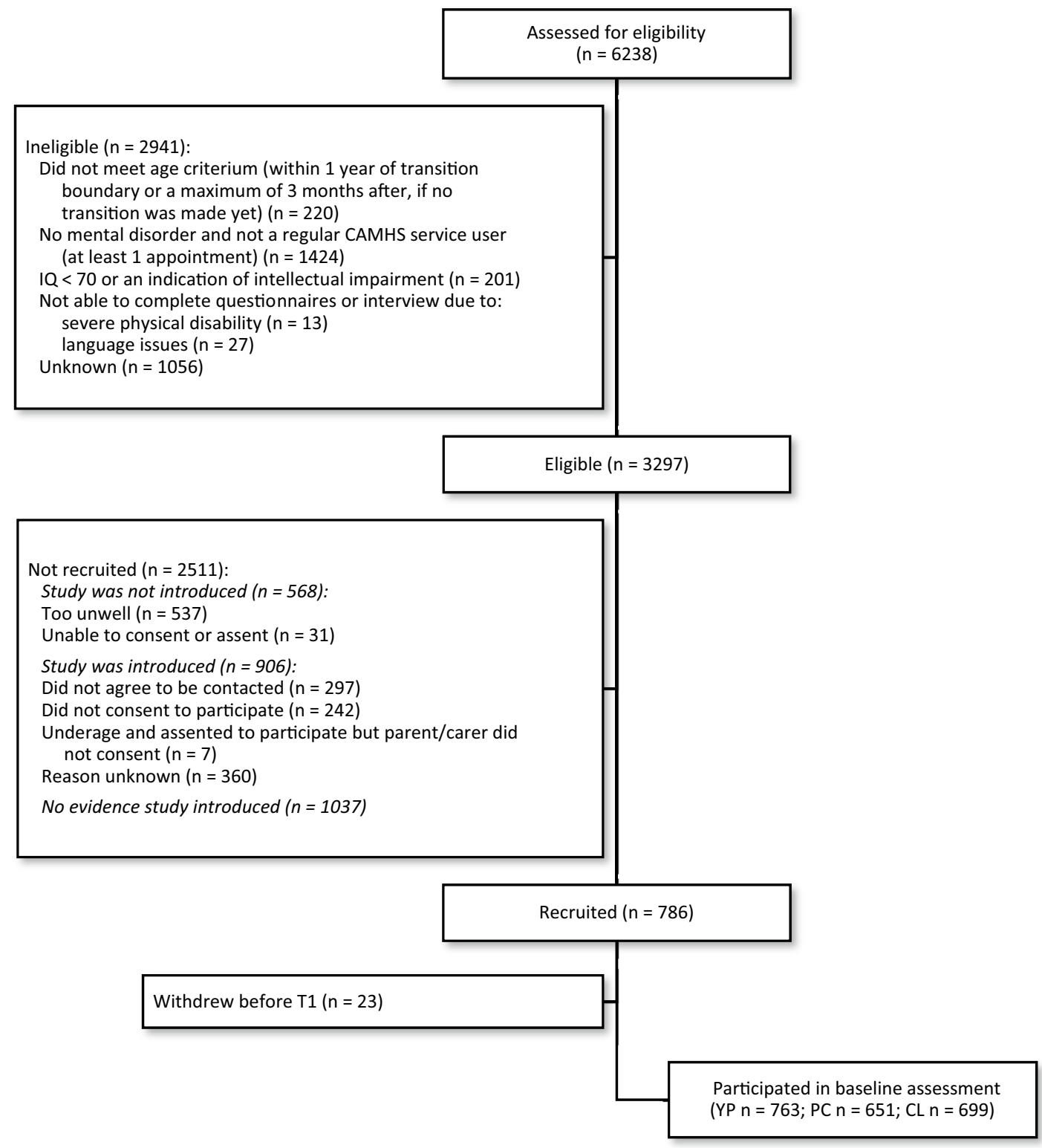

Note: $\mathrm{YP}=$ young person; $\mathrm{PC}=$ parent $/ \mathrm{carer} ; \mathrm{CL}=$ clinician. $\mathrm{A}$ total of 763 young people consented and participated in baseline assessments, which is $45.1 \%$ of all young people to whom the study was introduced (763/786+906).

Fig. 1 CONSORT flow diagram of participants

the local CAMHS, at home or over the phone. Questionnaires were administered online via the HealthTracker ${ }^{\mathrm{TM}}$ platform; paper copies were only used if HealthTracker could not be accessed. Clinicians completed questionnaires and/or medical records were accessed to provide clinical information on the young person. Data collected at baseline included information on demographic, family, clinical, treatment, and service-use characteristics as well as on transition recommendations.

\section{Measures}

\section{Demographic, family, clinical, treatment, and service-use characteristics}

Demographic and family characteristics included living situation, education/employment, and psychopathology in biological parents. Clinical characteristics included self- and parent-reported emotional/behavioural problems 
(collectively referred to as 'problem levels'), clinical classifications, clinician-rated severity of psychopathology, self-reported suicidal thoughts/behaviours or self-harm, selfreported psychotic experiences, and parent-reported everyday functional skills. Treatment and service-use characteristics included self-reported inpatient psychiatric service use, accident and emergency department service use, psychotropic medication use, self-reported length of CAMHS use, the availability of appropriate AMHS according to the clinician (i.e., a local AMHS service with the skills/resources to treat the young person's condition), and the need for ongoing treatment irrespective of the type of care or service indicated by young people and parents. All measures described in this paper were administered at baseline and are listed in Table 1 .

\section{Transition recommendations}

Transition recommendations by the clinician were assessed using the Transition Readiness and Appropriateness Measure [12] (TRAM; see Table 1). To study characteristics associated with continued care in general and a recommendation to continue care at AMHS specifically, the transition recommendation was dichotomised in two ways. The first indicated a recommendation for continuity of treatment within a mental healthcare setting (if the clinician indicated it was most appropriate to "continue treatment at current CAMHS service', 'continue treatment by other mental health services' or 'transition to AMHS') or discontinuity of treatment (if the clinician indicated it was most appropriate to 'discharge' or 'discharge to the general practitioner'). Second, if the recommendation was to continue treatment, response categories were collapsed to indicate whether continued care was recommended in CAMHS ('continue treatment at current CAMHS service' or 'continue treatment at other CAMHS') or AMHS ('transition to AMHS').

\section{Covariates}

Gender, highest level of parental education, and country were reported and included as covariates in the analyses to account for potential confounding by these characteristics.

\section{Statistical analyses}

Details on how the different measures were scored and applied in analyses are described in Table 1.

First, we assessed which demographic, family, clinical, treatment, and service-use-related characteristics of young people were associated with the clinician's treatment recommendations, by fitting logistic mixed models. Demographic, family, clinical, treatment, and service-use related characteristics were included as independent variables, and the clinician's recommendation was included as the dependent variable, dichotomized as needing continued mental health treatment versus not needing that treatment according to the clinician. Second, among young people who were recommended to continue mental health treatment, we used logistic mixed models to assess which demographic, family, clinical, treatment, and service-userelated characteristics were associated with being recommended to continue treatment at AMHS (i.e., to transition) versus CAMHS.

To account for potential confounding, all analyses were multivariate, and gender, parents' highest completed level of education, and country were added as covariates. 'Omnibus-tests' were conducted to test whether adding non-linear effects (cubic splines) and/or interactions between clinical classifications and gender need for ongoing treatment and length of CAMHS use improved model fit. If an omnibus test indicated interactions and/or non-linear effects significantly contributed to an improved model fit, additional analyses were conducted to assess which specific effects improved the model.

Model fit was assessed by comparing the fit of the final model to a covariate only model with a likelihood ratio test. Pooled odds ratios and corresponding 95\% confidence intervals were reported. The significance level was set at $\alpha=0.05$. Multicollinearity was not present, indicated by a maximum squared adjusted generalized variance inflation factor $\left(\operatorname{GVIF}^{\wedge}(1 /(2 * D f))\right.$, comparable to VIF) under 2. All statistical analyses were performed in R [13]. All models were fitted with site (CAMHS) as the only level and random intercepts (applying a likelihood estimator), using lme4 [14].

We assumed that data were missing at random (MAR), as we hypothesized that the missingness of an observation depended only on observed values. Previous analyses [11] support this assumption, as the missingness in data from parent-reported measures, which had largest proportion of missingness, was dependent on the observed values of self-reported and clinician-reported problem levels. To account for missing data under the MAR assumption, multiple imputation was applied on all variables included in the analyses before mixed models were fitted (accounting for clustering of the data; using mice [15] and miceadds [16]). The data were imputed using all variables included in the analyses described in this manuscript as predictor variables to estimate missing values. The variable 'site' (indicating the CAMHS in which the young person was recruited) was used as a cluster variable. The data were imputed with the default method in mice, after which density plots and trace lines were used to inspect the imputations and convergence, respectively. Following these inspections, the method of imputation was changed per variable, to see whether other methods improved the imputation. A total of 50 imputations were conducted with 20 iterations. 


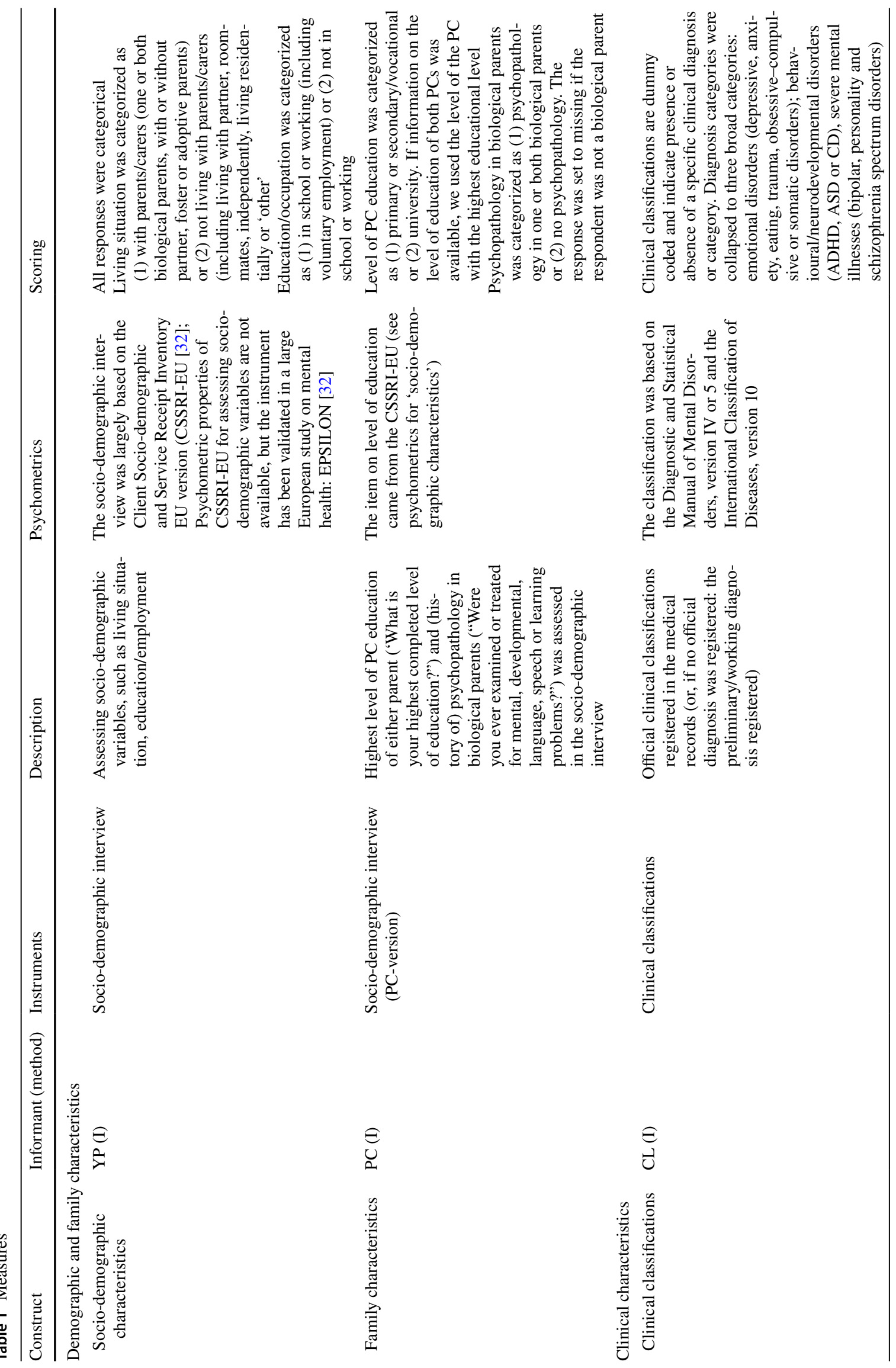




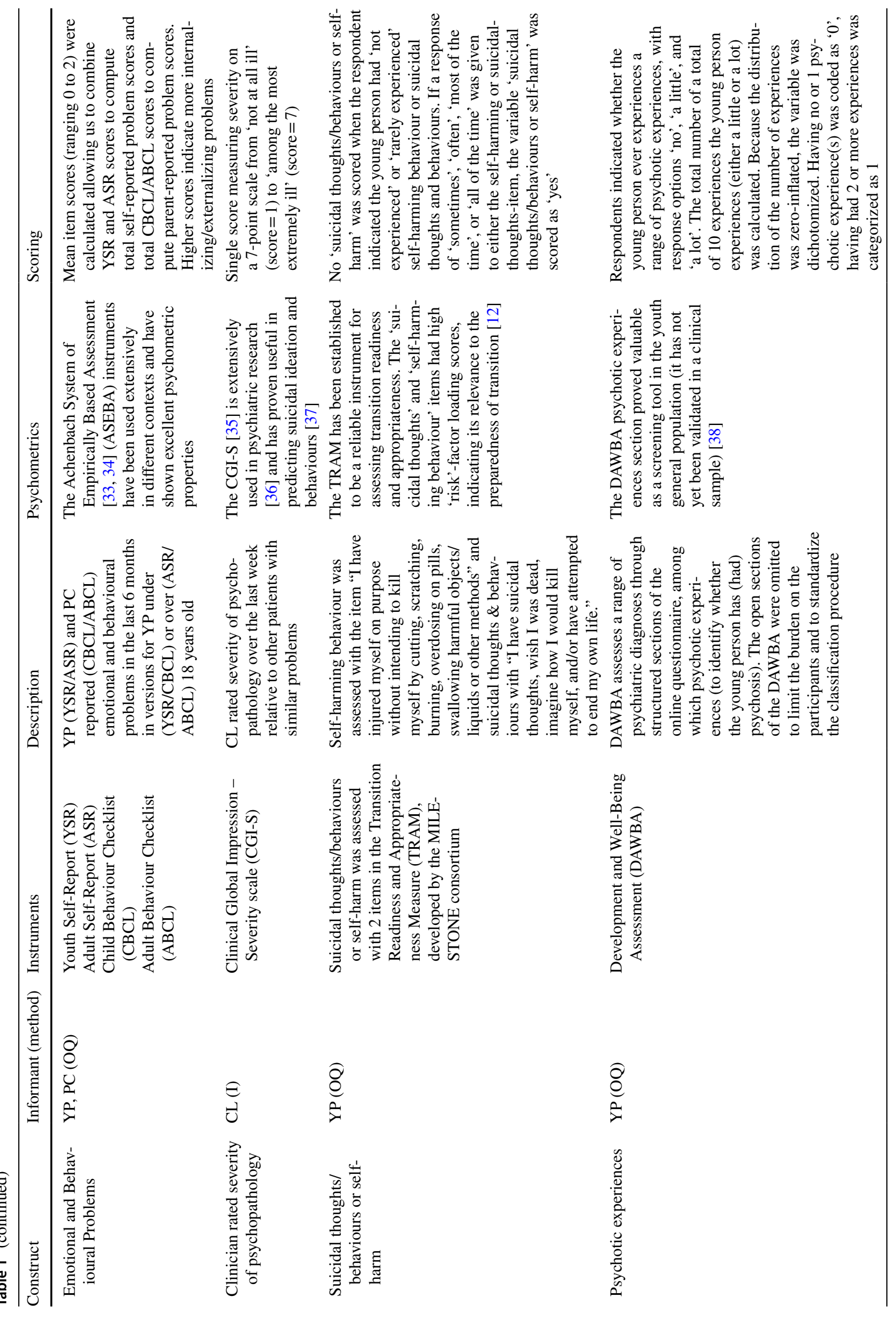




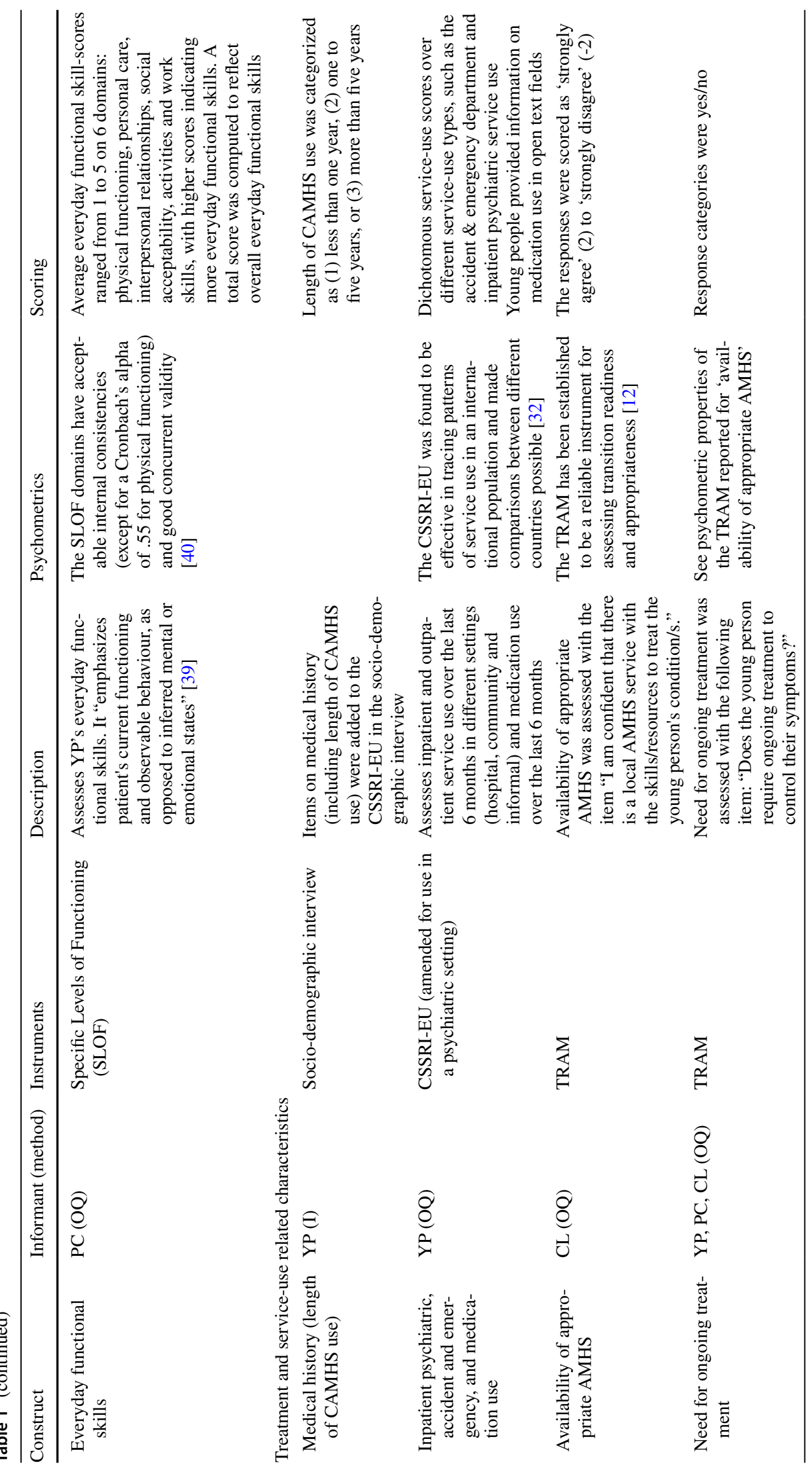




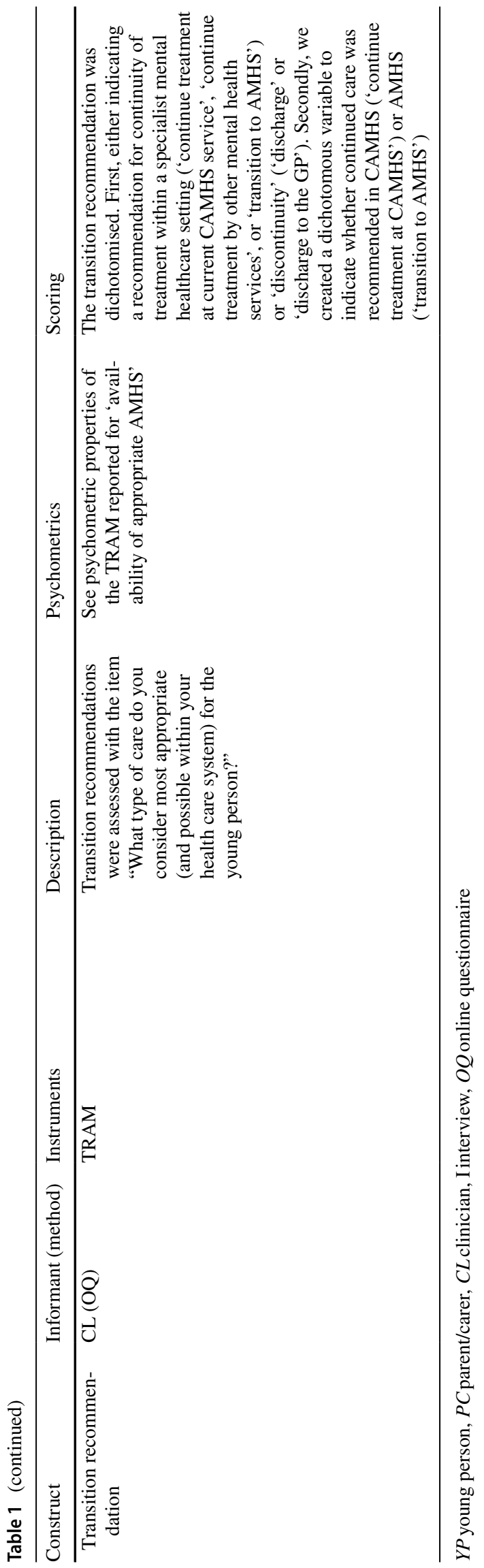

\section{Results}

A total of 763 young people were recruited to the MILESTONE cohort. Their mean age was 17.5 years $(S D=0.59$; ranging from 15.2 to 19.6$)$. A total of 458 young people $(60.0 \%)$ identified as female and $305(40 \%)$ identified as male.

\section{Clinician recommendations}

Clinicians recommended continuation of treatment within MHS for $460(60.3 \%)$ of young people. Of those who were recommended to continue treatment, $52.4 \%(n=241)$ were advised to stay in CAMHS, $32.4 \%(n=149)$ to transition and continue treatment at AMHS, and $15.2 \%(n=70)$ were recommended to continue treatment in 'other' MHS (not specifically CAMHS or AMHS). Clinicians recommended discharge or referral to the GP for 180 young people $(23.6 \%)$. Information on the clinician's recommendation was missing for $123(16.1 \%)$.

\section{Characteristics associated with the clinician recommendation to continue treatment within mental health services}

Table 2 shows descriptive characteristics of 640 young people without missing data on the clinician's recommendation, as well as the results from the first analysis, conducted on imputed data $(n=763)$ : the demographic, family, clinical, treatment, and service-use characteristics associated with the recommendation to continue care in MHS (CAMHS, AMHS, or other MHS) or to discontinue (referral to general practitioner or discharge). The model with the best model fit included a natural cubic spline for the severity of psychopathology score and did not include interactions, and predicted a recommendation of continued treatment significantly better than the covariate only model $(p<0.001)$.

A higher severity of psychopathology score significantly predicted a recommendation for continued treatment within MHS. Self- and parent-reported emotional/behavioural problems were not associated with the clinician's recommendation to continue treatment, but a young person or parent indicating a need for ongoing treatment did increase the odds of the clinician recommending continuation of treatment within MHS by more than 2. A clinical classification of a severe mental disorder or self-reported suicidal thoughts/ behaviours or self-harm were not associated with the clinician's recommendation. Additionally, young people who had more than one psychotic experience had $71 \%$ decrease in the odds of being recommended to continue treatment. Young people with more everyday functional skills were 2.5 times less likely to be recommended to continue treatment. Demographic and family characteristics such as having a 
job, attending school, or the living situation, were not associated with the clinician's recommendation.

\section{Unplanned explorative analyses on psychotic experiences}

As the negative association between self-reported psychotic experiences and a recommendation to continue treatment was surprising, we conducted additional explorative bivariate analyses (Welch two-sample $t$ tests) to gain insight in the differences between young people with selfreported psychotic experiences who were recommended to continue treatment and those who were not. We found that young people who reported psychotic experiences but were not recommended to continue treatment had lower clinician-rated severity of psychopathology scores $(t(77.962)=-8.989 ; p<0.001)$ and lower research-assistant rated scores on the HoNOSCA 'hallucinations and delusions' domain $(t(95.366)=-2.877 ; p=0.005)$, than young people who reported psychotic experiences who were recommended to continue treatment (these analyses were conducted on observed data). Additionally, young people who reported psychotic experiences and were recommended to continue treatment were more likely to have a clinical classification of a severe mental disorder $(t(122.11)=-3.873 ; p<0.001)$ than young people who reported psychotic experiences, but were not recommended to continue treatment. There were no differences between these groups with regard to behavioural/neurodevelopmental disorders $(t(64.078)=0.012 ; p=0.991)$ and emotional disorders $(t(64.966)=0.177 ; p=0.860)$.

\section{Characteristics associated with the transition recommendation to continue treatment at AMHS}

Among those for whom continued treatment in MHS was recommended, a differentiation was made between those who were recommended to continue treatment within CAMHS ( $n=241)$ versus those who were recommended to transition to AMHS $(n=249)$. Table 3 shows demographic, family, clinical, treatment, and service-use characteristics of both groups. To assess how these characteristics of young people at baseline were associated with transition decisions, a model predicting the clinician's recommendation for continued treatment at AMHS was established. The model with the best model fit did not include interactions or non-linear effects and predicted a recommendation to AMHS significantly better than the covariate only model $(p=0.004)$. Odds ratios and associated confidence intervals for this model are presented in Table 3.

Neither clinician-rated psychopathology, nor self- or parent-reported emotional/behavioural problems were associated with the clinician's recommendation to transition to AMHS. The odds of the young person being recommended to transition to AMHS decreased by $66 \%$ when parents indicated a need for ongoing treatment, or alternatively: they were more likely to be recommended to stay in CAMHS. Having a severe mental disorder, self-reported suicidal thoughts/behaviours or self-harm, or self-reported psychotic experiences were not associated with the recommendation to transition to AMHS, nor were everyday functional skills, working or being in school and living independently. Medication use emerged as an important factor-young people who used psychotropic medication had over twice greater odds of being recommended to transition to AMHS. The length of time in CAMHS was also important: for young people who had been in CAMHS treatment for more than 1 year, the odds of being recommended to transition to AMHS doubled compared to young people who had been in treatment at CAMHS for less than a year. Having been at CAMHS for more than 5 years tripled the odds of being recommended to transition to AMHS compared to those in care less than a year. The clinician indicating appropriate AMHS were available for treatment of the young person increased the odds by $63 \%$.

\section{Discussion}

This study describes associations between demographic, family, clinical, treatment, and service-use related characteristics and the clinicians' recommendation regarding continuity of care in a sample of young people who reached the upper age limit of their CAMHS. We found that the recommendation to continue treatment was primarily determined by clinician-reported severity of psychopathology and selfand parent-reported need for ongoing treatment, whereas the recommendation to continue treatment at AMHS rather than CAMHS was associated with treatment and service-userelated characteristics only, such as the length of CAMHS use and the availability of appropriate AMHS. In contrast with findings from some previous studies $[6,7,17]$, an association between demographic and family characteristics and the recommendation to continue treatment at AMHS could not be confirmed. As both parental psychopathology [18] and not being in education, employment, or training are associated with negative mental health outcomes among young adults $[19,20]$, it is surprising that these characteristics are not considered in the clinician's transition decision.

Clinician rated severity of psychopathology and selfand parent-reported need for ongoing treatment had the strongest associations with a recommendation to continue treatment. Although we expected clinician-reported problem level to be more strongly associated with the clinician's recommendation to continue treatment than self- or parentreported problem levels, due to shared source variance, 
Table 2 Demographic and family, clinical, and treatment and service characteristics in relation to transition recommendations regarding continuity of care (descriptives and model summary)

\begin{tabular}{lllll}
$\begin{array}{l}\text { Characteristics (original non-imputed } \\
\text { data) }\end{array}$ & & $\begin{array}{l}\text { Model summary (on } \\
\text { imputed data)* }\end{array}$ \\
\cline { 1 - 1 } & Disc. $(n=180)$ & Cont. $(n=460)$ & & OR $95 \%$ CI \\
\hline
\end{tabular}

Demographic and family characteristics

Living situation $(n(\%))$

Not living with parents/carers

Living with parents/carers

Missing

Education/employment $(n(\%))$

Not in school or working

In school or working

Missing

Psychopathology in biological parents (n (\%))

No psychopathology

Psychopathology in one or both biological parents

Missing

Clinical characteristics

Self-reported total emotional/ behavioural problems (mean (SD))

Parent/carer-reported total emotional/ behavioural problems (mean (SD))

Clinical classifications $(n(\%))$

Emotional disorder ${ }^{1}$

Behavioural/neurodevelopmental disorder ${ }^{2}$

Severe mental illness ${ }^{3}$

Clinician rated severity of psychopathology (mean (SD) $)^{4}$

ns (CGIS, 3) 1

ns (CGIS, 3)2

ns (CGIS, 3) 3

Suicidal thoughts/behaviours or self-harm $(n(\%))$

None

Suicidal thoughts/behaviours or self-harm

Missing

Psychotic experiences $^{5}(n(\%))$

0 or 1 experience(s)

2-16 experiences

Missing

Everyday functional skills (mean (SD))

Treatment and service use

Inpatient psychiatric service use $(n(\%))$

No

Yes

Missing

Accident and emergency department service use ( $n(\%))$

No

Yes

Missing

Psychotropic medication use $(n(\%))$

No

Yes

Missing

Length of CAMHS use ${ }^{6}(n(\%))$
716

$8(4.4)$

$171(95.0) \quad 396(86.1)$

$1(0.6) \quad 17(3.7)$

713

$7(3.9) \quad 41(8.9)$

$170(94.4) \quad 401(87.2)$

$3(1.7) \quad 18(3.9)$

545

$96(53.3) \quad 225(48.9)$

$47(26.1) \quad 121(26.3)$

$37(20.6) \quad 114(24.8)$

$\begin{array}{lll}683 & 0.50(0.27) & 0.58(0.28)\end{array}$

$0.42(0.24)$

734

$107(59.4) \quad 284(61.7)$

$54(30.0) \quad 170(37.0)$

$8(4.4) \quad 77(16.7)$

$640 \quad 2.26(1.08) \quad 3.89(1.24)$

$\begin{array}{lll}36.02 & 9.86 & 131.65^{\#}\end{array}$

$\begin{array}{lll}171.75 & 17.79 & 1657.97\end{array}$

$\begin{array}{lll}19.91 & 1.27 & 310.97\end{array}$

626

$117(65.0) \quad 230(50.0)$

$60(33.3) \quad 210(45.7)$

$\begin{array}{lll}1.86 & 0.92 \quad 3.75\end{array}$

$3(1.7)$

$20(4.3)$

$104(57.8) \quad 274(59.6)$

37 (20.6) $\quad 99(21.5)$

39 (21.7) $\quad 87(18.9)$

$5774.58[4.33,4.81] \quad 4.40[4.05,4.67]$

$0.29 \quad 0.13$

0.62

$\begin{array}{lll}0.39 & 0.17 & 0.88\end{array}$

666

$164(91.1) \quad 358(77.8)$

$1(0.6) \quad 56(12.2)$

$15(8.3) \quad 46(10.0)$

666

$143(79.4) \quad 362(78.7)$

$22(12.2) \quad 52(11.3)$

$15(8.3) \quad 46(10.0)$

666

$84(46.7) \quad 152(33.0)$

$81(45.0) \quad 262(57.0)$

$15(8.3) \quad 46(10.0)$ $\begin{array}{lll}0.73 \quad 0.32 & 1.66\end{array}$

$1.22 \quad 0.66$

2.25 $\begin{array}{lll}1.77 & 0.39 & 7.96\end{array}$ 
Table 2 (continued)

\begin{tabular}{|c|c|c|c|c|c|c|}
\hline & \multicolumn{3}{|c|}{$\begin{array}{l}\text { Characteristics (original non-imputed } \\
\text { data) }\end{array}$} & \multicolumn{3}{|c|}{$\begin{array}{l}\text { Model summary (on } \\
\text { imputed data)* }\end{array}$} \\
\hline & $n$ & Disc. $(n=180)$ & Cont. $(n=460)$ & OR & $95 \% \mathrm{CI}$ & \\
\hline$<1 \mathrm{yr}$ & & $39(21.7)$ & $123(26.7)$ & & & \\
\hline $1-5 \mathrm{yrs}$ & & $88(48.9)$ & $207(45.0)$ & 0.80 & 0.41 & 1.55 \\
\hline$>5 \mathrm{yrs}$ & & $51(28.3)$ & $104(22.6)$ & 0.51 & 0.23 & 1.17 \\
\hline Missing & & $2(1.1)$ & $26(5.7)$ & & & \\
\hline Availability of appropriate AMHS (mean (SD)) & 640 & $0.28(1.16)$ & $0.30(1.15)$ & 1.14 & 0.89 & 1.45 \\
\hline YP indicating need for ongoing treatment $(n(\%))$ & 716 & & & & & \\
\hline No & & $106(58.9)$ & $139(30.2)$ & & & \\
\hline Yes & & $71(39.4)$ & $301(65.4)$ & 1.91 & 1.08 & 3.38 \\
\hline Missing & & $3(1.7)$ & $20(4.3)$ & & & \\
\hline PC indicating need for ongoing treatment $(n(\%))$ & 579 & & & & & \\
\hline No & & $81(45.0)$ & $88(19.1)$ & & & \\
\hline Yes & & $69(38.3)$ & $276(60.0)$ & 2.44 & 1.26 & 4.74 \\
\hline Missing & & $30(16.7)$ & $96(20.9)$ & & & \\
\hline
\end{tabular}

Logistic mixed model was fitted with site as the only level and random intercepts (applying a likelihood estimator), displaying odds of continued treatment within MHS recommended versus with no continued treatment within MHS recommended as the reference group. Gender, parental educational level and country were added as covariates

$Y P$ young person, $P C$ parent/carer, Cont . recommendation to continue treatment, Disc. recommendation to discontinue treatment

${ }^{1}$ Combination of depressive, anxiety, eating, trauma, obsessive-compulsive, and somatic disorders

${ }^{2}$ Combination of ADHD, ASD and CD

${ }^{3}$ Combination of bipolar, personality and schizophrenia spectrum disorders

${ }^{4}$ The effect of clinician-rated severity of psychopathology was non-linear, with a natural cubic spline. The effect was strongest for the third spline (ns(CGIS, 3)3) indicating the slope of the effect was steepest around scores 3 and 4

${ }^{5}$ Reference category is 0 or 1 psychotic experience(s)

${ }^{6}$ Reference category is less than 1 year

$*_{n}$ changes depending per imputed dataset

${ }^{\text {\#}}$ The confidence intervals for splines are large, but this is not uncommon. As the coefficients for splines do not have a very direct interpretation, the effects of the splines of clinician-rated psychopathology are visually presented in the effect plot in the supplementary material

the lack of an association between self- or parent-reported problem levels and the clinician's transition recommendation was unexpected. As self- or parent-reported need for ongoing treatment was very strongly associated with the clinician's recommendation, it might have suppressed the effects of self- and parent-reported problem levels in the multivariate model, resulting in non-significant effects. Even though self- and parent-reported problem levels were not associated with transition recommendations, our findings indicate that the need for ongoing treatment expressed by young people and parents are important factors in the transition decision. Fortunately, as the importance of including their perspective on the need for ongoing treatment has been emphasized by young people and parents $[21,22]$.

In contrast to findings from other studies [4, 6, 9, 17], having a clinical classification of a severe mental disorder did not increase the odds of being recommended to continue treatment. Suicidal thoughts/behaviours or self-harm, indicators of severe and acute problems, were not significantly associated with a recommendation to continue treatment either. Also, counterintuitively, two or more self-reported psychotic experiences were negatively associated with a recommendation to continue treatment. A possible explanation is that in a multivariate model with a strong general index for psychopathology, i.e., clinician-rated severity of psychopathology, the associations with other clinical markers for severity of psychopathology, such as having a severe mental disorder, suicidal thoughts/behaviours or self-harm and psychotic experiences, are suppressed. With regard to psychotic experiences, this explanation is supported by previous findings that self-reported psychotic experiences in the general population can be considered a clinical marker for severity of psychopathology [3, 23]. Although the presence of suicidality and psychotic experiences may be reflected in the clinicians' assessment of severity of psychopathology, the additional explorative analyses showed that clinicians may not have been aware of the young person's psychotic experiences in some cases, which may have affected their transition recommendations. 
Table 3 Demographic and family, clinical, and treatment and service characteristics in relation to transition recommendations regarding continued treatment in CAMHS versus AMHS (descriptives and model summary)

\begin{tabular}{|c|c|c|c|c|c|c|}
\hline & \multirow[t]{2}{*}{$n$} & \multicolumn{2}{|c|}{$\begin{array}{l}\text { Characteristics (original non-imputed } \\
\text { data) }\end{array}$} & \multicolumn{3}{|c|}{$\begin{array}{l}\text { Model summary } \\
\text { (on imputed data)* }\end{array}$} \\
\hline & & CAMHS $(n=241)$ & AMHS $(n=149)$ & OR & $95 \% \mathrm{C}$ & \\
\hline \multicolumn{7}{|l|}{ Demographic and family characteristics } \\
\hline Living situation $(n(\%))$ & 716 & & & & & \\
\hline Not living with parents/carers & & $27(11.2)$ & $14(9.4)$ & & & \\
\hline Living with parents/carers & & $210(87.1)$ & $131(87.9)$ & 1.15 & 0.45 & 2.96 \\
\hline Missing & & $4(1.7)$ & $4(2.7)$ & & & \\
\hline Education/employment $(n(\%))$ & 713 & & & & & \\
\hline Not in school or working & & $20(8.3)$ & $15(10.1)$ & & & \\
\hline In school or working & & $215(89.2)$ & $130(87.2)$ & 0.95 & 0.34 & 2.69 \\
\hline Missing & & $6(2.5)$ & $4(2.7)$ & & & \\
\hline Psychopathology in biological parents ( $n(\%))$ & 545 & & & & & \\
\hline No psychopathology & & $125(51.9)$ & $67(45.0)$ & & & \\
\hline Psychopathology in one or both biological parents & & $62(25.7)$ & $47(31.5)$ & 0.94 & 0.48 & 1.84 \\
\hline Missing & & $54(22.4)$ & $35(23.5)$ & & & \\
\hline \multicolumn{7}{|l|}{ Clinical characteristics } \\
\hline Self-reported total emotional/ behavioural problems (mean (SD)) & 683 & $0.56(0.26)$ & $0.60(0.30)$ & 0.75 & 0.20 & 2.80 \\
\hline Parent/carer-reported total emotional/ behavioural problems (mean (SD)) & 572 & $0.38(0.22)$ & $0.47(0.25)$ & 4.59 & 0.80 & 26.4 \\
\hline Clinical classifications $(n(\%))$ & 734 & & & & & \\
\hline Emotional disorder ${ }^{1}$ & & $154(63.9)$ & $91(61.1)$ & 1.33 & 0.67 & 2.64 \\
\hline Behavioural/neuro- developmental disorder ${ }^{2}$ & & $82(34.0)$ & $63(42.3)$ & 1.63 & 0.74 & 3.60 \\
\hline Severe mental illness ${ }^{3}$ & & $38(15.8)$ & $27(18.1)$ & 1.59 & 0.70 & 3.60 \\
\hline Clinician rated severity of psychopathology (mean (SD)) & 640 & $3.84(1.27)$ & $3.94(1.17)$ & 1.27 & 0.98 & 1.65 \\
\hline Suicidal thoughts/behaviours or self-harm $(n(\%))$ & 626 & & & & & \\
\hline None & & $128(53.1)$ & $73(49.0)$ & & & \\
\hline Suicidal thoughts/behaviours or self-harm & & $108(44.8)$ & $67(45.0)$ & 1.12 & 0.56 & 2.22 \\
\hline Missing & & $5(2.1)$ & $9(6.0)$ & & & \\
\hline \multicolumn{7}{|l|}{ Psychotic experiences $^{4}(n(\%))$} \\
\hline 0 or 1 experience(s) & & $152(63.1)$ & $84(56.4)$ & & & \\
\hline $2-16$ experiences & & $49(20.3)$ & $35(23.5)$ & 1.29 & 0.59 & 2.78 \\
\hline Missing & & $40(16.6)$ & $30(20.1)$ & & & \\
\hline Everyday functional skills (mean (SD)) & 577 & $4.42[4.14,4.67]$ & $4.27[3.84,4.65]$ & 1.15 & 0.51 & 2.57 \\
\hline \multicolumn{7}{|l|}{ Treatment/service-use } \\
\hline Inpatient psychiatric service use $(n(\%))$ & 666 & & & & & \\
\hline No & & $196(81.3)$ & $110(73.8)$ & & & \\
\hline Yes & & $26(10.8)$ & $21(14.1)$ & 1.96 & 0.77 & 4.97 \\
\hline Missing & & $19(7.9)$ & $18(12.1)$ & & & \\
\hline Accident and emergency department service use $(n(\%))$ & 666 & & & & & \\
\hline No & & $194(80.5)$ & $112(75.2)$ & & & \\
\hline Yes & & $28(11.6)$ & $19(12.8)$ & 1.14 & 0.44 & 2.95 \\
\hline Missing & & $19(7.9)$ & $18(12.1)$ & & & \\
\hline Psychotropic medication use $(n(\%))$ & 666 & & & & & \\
\hline No & & $98(40.7)$ & $36(24.2)$ & & & \\
\hline Yes & & $124(51.5)$ & $95(63.8)$ & 2.20 & 1.09 & 4.42 \\
\hline Missing & & $19(7.9)$ & $18(12.1)$ & & & \\
\hline Length of CAMHS use ${ }^{5}(n(\%))$ & 703 & & & & & \\
\hline$<1 \mathrm{yr}$ & & $85(35.3)$ & $23(15.4)$ & & & \\
\hline $1-5$ yrs & & $106(44.0)$ & $74(49.7)$ & 2.01 & 1.02 & 3.98 \\
\hline$>5 \mathrm{yrs}$ & & $41(17.0)$ & $46(30.9)$ & 3.11 & 1.23 & 7.89 \\
\hline
\end{tabular}


Table 3 (continued)

\begin{tabular}{|c|c|c|c|c|c|c|}
\hline & \multirow[t]{2}{*}{$n$} & \multicolumn{2}{|c|}{$\begin{array}{l}\text { Characteristics (original non-imputed } \\
\text { data) }\end{array}$} & \multicolumn{3}{|c|}{$\begin{array}{l}\text { Model summary } \\
\text { (on imputed data)* }\end{array}$} \\
\hline & & CAMHS $(n=241)$ & AMHS $(n=149)$ & OR & $95 \% \mathrm{C}$ & \\
\hline Missing & & $9(3.7)$ & $6(4.0)$ & & & \\
\hline Availability of appropriate AMHS (mean (SD)) & 640 & $0.12(1.16)$ & $0.57(1.08)$ & 1.63 & 1.25 & 2.13 \\
\hline YP indicating need for ongoing treatment $(n(\%))$ & 716 & & & & & \\
\hline No & & $75(31.1)$ & $47(31.5)$ & & & \\
\hline Yes & & $161(66.8)$ & $93(62.4)$ & 0.75 & 0.39 & 1.45 \\
\hline Missing & & $5(2.1)$ & $9(6.0)$ & & & \\
\hline PC indicating need for ongoing treatment $(n(\%))$ & 579 & & & & & \\
\hline No & & $41(17.0)$ & $35(23.5)$ & & & \\
\hline Yes & & $154(63.9)$ & $86(57.7)$ & 0.34 & 0.16 & 0.73 \\
\hline Missing & & $46(19.1)$ & $28(18.8)$ & & & \\
\hline
\end{tabular}

Logistic mixed model was fitted with site as the only level and random intercepts (applying a likelihood estimator), displaying odds of continued treatment at AMHS recommended versus with continued treatment within CAMHS recommended as the reference group. Gender, parental educational level and country were added as covariates

$Y P$ young person, $P C$ parent/carer

${ }^{1}$ Combination of depressive, anxiety, eating, trauma, obsessive-compulsive, and somatic disorders

${ }^{2}$ Combination of ADHD, ASD, and CD

${ }^{3}$ Combination of bipolar, personality, and schizophrenia spectrum disorders

${ }^{4}$ Reference category is 0 or 1 psychotic experience(s)

${ }^{5}$ Reference category is less than 1 year

* $n$ changes depending per imputed dataset

A clinical characteristic not studied previously was everyday functional skills, which were negatively associated with a recommendation to continue treatment. Young people with more everyday functional skills were more likely to be discharged or referred to other mental health services. Interestingly, whereas self-reported and parent-reported need for ongoing treatment were associated with the clinician's recommendation to continue care, only parent-reported need for ongoing treatment was associated with the recommendation to continue treatment at AMHS. As parent-reported need for ongoing treatment was negatively associated with the recommendation to continue treatment at AMHS (and positively with continuing treatment in CAMHS), it may be that parent-reported need for ongoing treatment is associated with the involvement of parents in the young person's treatment. As a systemic approach to treatment in which parents have an important role is more common in CAMHS than in AMHS [24], the involvement of parents may be a reason for the CAMHS clinician to continue treatment in CAMHS, rather than to refer the young person to AMHS. Alternatively, parents involved in the young person's treatment may appeal to the CAMHS clinician to let the young person continue treatment in CAMHS, as they may be uncertain of what care in AMHS entails.

Treatment and service-use-related characteristics, such as psychotropic medication use and the length of service use within CAMHS, were specifically associated with a recommendation to AMHS. Findings from previous studies investigating these characteristics in relation to referral to AMHS have been inconsistent $[4,6,7]$, due to differences in the operationalization of both medication use and length of CAMHS use, and differences in applied statistical analyses. It may be that psychotropic medication use and a longer length of treatment within CAMHS are indication of more severe and chronic psychopathology, requiring long-term treatment and a referral to AMHS. In some cases, the prescription and continuation of psychotropic medication might require contact with a specialist service such as an AMHS (e.g., the continuation of ADHD medication requires hospital contact at least once a year in France). Our findings also show that the CAMHS clinicians' recommendation depends on their perspective on the availability of local AMHS services with the right skills and resources for some young people. Previous studies showed that CAMHS clinicians may not refer a young person to AMHS if they consider AMHS not to have the right expertise or will not accept certain referrals due to eligibility criteria [17, 25]. For instance, some AMHS may not accept referrals if they consider the young person to be 'not ill enough' [26] or eligibility criteria may exclude young people with specific diagnoses, such as neurodevelopmental disorders. Alternatively, clinicians may be unaware of the services offered by AMHS in the area, which may also affect the clinician's transition decision. 


\section{Strengths and limitations}

This paper provides insight in the demographic and family, clinical and treatment, and service-use related characteristics that potentially play a role in the CAMHS clinician's recommendation regarding continuity of treatment and transition to AMHS. The use of standardized assessments and young person and parent reports allowed us to reliably assess a large range of characteristics from the perspective of the young person, parent, and clinician. We conducted multivariate analyses with a large range of different predictors, accounting for most known potential confounders. There are several limitations to the findings reported in this study, as well. The limitations with regard to the recruitment process, representativeness, and generalizability were elaborately discussed in a paper describing the cohort profile [11] and will be discussed only briefly in this paper. First, a selection bias may exist due to several reasons: the selection of CAMHS participating in MILESTONE were not made randomly, but should be considered a convenience sample, the response rate was $45.1 \%$ (although other cohort studies on adolescents with mental health problems report similar response rates [27-29]) and the proportion of missing information, particularly among parents, is considerable. The response rate of $45.1 \%$ may be an overestimation of the true response rate that we would have obtained if information on the recruitment process was complete, but this estimate most accurately reflects the process. Due to medical ethical constraints, our recruitment methods relied on medical records and clinicians to assess eligibility and inclusion criteria, as well as to inform and gain consent from participants. Therefore, information on the recruitment process was incomplete. It was not possible to assess whether a selection bias exists with a nonresponse analysis, as the medical ethical committee did not allow us to collect data of non-responders without informed consent and very few young people consented to using this basic medical data. A previous analysis of missing data among participants [11] indicated a potential bias in participation of parents, who were less likely to complete all measures when their children reported more self-reported problems and clinicians reported more severe psychopathology. We applied multiple imputation to account for (a selection in) missingness in assessments. Ultimately, however, representativeness is not necessarily required to generalize our findings to other clinical populations of young people in the transition age [30]. Drawing reliable conclusions on the relationships between variables is possible if potential variables on which a selection could have taken place, such as parental educational level, country, gender, or severity of psychopathology are included in the analyses conducted, which was the case in the present study [31]. A selection bias to affect the generalizability of the findings from this study is therefore less likely. By recruiting young people from a wide range of CAMHS in different European countries, varying in size and ranging from community to specialist and/or academic hospital-based services in countries with differences in mental health service organization (i.e., more or less segmented services), culture, training, and concepts of mental health, our findings can be generalized independent of service type or European country. Replication of our study outside the European context is important to assess generalizability of our findings to other continents.

Finally, transition recommendations and need for ongoing treatment were assessed with a single item, part of the recently validated Transition Readiness and Appropriateness Measure [12]. To our knowledge, no other validated measures are available to assess these constructs. However, this could be considered a weakness of the study. Information on the clinician's transition recommendations was missing for $16.1 \%$ of young people, but this is unlikely to impact the results of our study due to the application of multiple imputation.

\section{Conclusion and recommendations}

In conclusion, the decision regarding continuity of treatment was most prominently determined by a small set of clinical characteristics, whereas none of these clinical characteristics determined whether transition to AMHS was recommended. Even though demographic and family characteristics may be important predictors of mental health outcomes, these characteristics are not considered in the clinician's decisionmaking process. As the availability of appropriate AMHS was shown to be an important factor in the clinician's transition decision, it is important that national and local governments guarantee AMHS availability and ensure that AMHS eligibility criteria meet the needs of young people with an ongoing need for treatment reaching the upper age limit of their CAMHS. Additionally, we recommend implementing standardized assessments of self- and parent-reported problems, including suicidality and psychotic experiences, in the period before young people reach the upper age limit of their CAMHS. Future analyses on MILESTONE cohort data will focus on the process of transition that follows the CAMHS clinician's decision regarding transition, and will assess whether the clinician's decision appropriately identifies young people who need ongoing treatment after reaching the upper age limit of CAMHS. Future analyses will also show which characteristics are associated with actually making a transition to AMHS or, alternatively, experiencing an unplanned discontinuity of treatment, as well as associated mental health outcomes.

Supplementary Information The online version contains supplementary material available at https://doi.org/10.1007/s00127-022-02238-6.

Acknowledgements We thank all the young people, parents and clinicians for participating in the MILESTONE study. We would also like to extend our thanks to the teams within the collaborating CAMHS and AMHS. We extend a special thanks to the young project advisors, the 
members of the MILESTONE Scientific Clinical and Ethical Advisory Board and Jane Warwick. We also thank everyone who was temporarily part of the wider MILESTONE team, as well as all the students who contributed to the data-collection. Finally, we thank all members of the wider MILESTONE consortium for their contribution.

The wider MILESTONE consortium includes the following collaborators (including the members listed as authors): Laura Adams, Giovanni Allibrio, Marco Armando, Sonja Aslan, Nadia Baccanelli, Monica Balaudo, Fabia Bergamo, Angelo Bertani, Jo Berriman, Albert Boon, Karen Braamse, Ulrike Breuninger, Maura Buttiglione, Sarah Buttle, Aurélie Schandrin, Marco Cammarano, Alastair Canaway, Fortunata Cantini, Cristiano Cappellari, Marta Carenini, Giuseppe Carrà, Cecilia Ferrari, Krizia Chianura, Philippa Coleman, Annalisa Colonna, Patrizia Conese, Raffaella Costanzo, Claire Daffern, Marina Danckaerts, Andrea de Giacomo, Jean-Pierre Ermans, Alan Farmer, Jörg M Fegert, Sabrina Ferrari, Giuliana Galea, Michela Gatta, Elisa Gheza, Giacomo Goglia, MariaRosa Grandetto, James Griffin, Flavia Micol Levi, Véronique Humbertclaude, Nicola Ingravallo, Roberta Invernizzi, Caoimhe Kelly, Meghan Killilea, James Kirwan, Catherine Klockaerts, Vlatka Kovač, Ashley Liew, Christel Lippens, Francesca Macchi, Lidia Manenti, Francesco Margari, Lucia Margari, Paola Martinelli, Leighton McFadden, Deny Menghini, Sarah Miller, Emiliano Monzani, Giorgia Morini, Todor Mutafov, Lesley O'Hara, Cristina Negrinotti, Emmanuel Nelis, Francesca Neri, Paulina Nikolova, Marzia Nossa, Maria Giulia Cataldo, Michele Noterdaeme, Francesca Operto, Vittoria Panaro, Adriana Pastore, Vinuthna Pemmaraju, Ann Pepermans, Maria Giuseppina Petruzzelli, Anna Presicci, Catherine Prigent, Francesco Rinaldi, Erika Riva, Anne Roekens, Ben Rogers, Pablo Ronzini, Vehbi Sakar, Selena Salvetti, Ottaviano Martinelli, Tanveer Sandhu, Renate Schepker, Marco Siviero, Michael Slowik, Courtney Smyth, Patrizia Conti, Maria Antonietta Spadone, Fabrizio Starace, Patrizia Stoppa, Lucia Tansini, Cecilia Toselli, Guido Trabucchi, Maria Tubito, Arno van Dam, Hanne Van Gutschoven, Dirk van West, Fabio Vanni, Chiara Vannicola, Cristiana Varuzza, Pamela Varvara, Patrizia Ventura, Stefano Vicari, Stefania Vicini, Carolin von Bentzel, Philip Wells, Beata Williams, Marina Zabarella, Anna Zamboni \& Edda Zanetti.

Author contributions SEG and LSB prepared the first draft and subsequent versions of this manuscript, under supervision of MMO, GCD, $\mathrm{AM}$, and FCV and in collaboration with DW. DR provided statistical consultation with regard to the conceptualization of the data-analysis plan, execution of the analyses, and write-up. SPS, AM, GDG, PS, JM, FM, DP-O, ST, US, TF, CS, MP, DW, FCV, and GCD conceived the original study design, obtained funding, and/or acted as principal investigators. HT was the study coordinator. PT, SEG, LSB, GS, FR, ND, VR, MM, RA, and NH were research assistants who helped set up the study in their countries, gain local ethical approvals, and collected data. TvA, CBR, FBB, IC, DDF, KDC, AF, GH, RJ, HLP, KL, VM, RN, AP, LR, MS, ISO, AS, PSc, JS, MS, PStagi, PStagni, and ET also contributed to local sites set-up and data-collection. CG, AT, AW, and $\mathrm{LW}$ were young project advisors. AK and FF contributed on behalf of HealthTracker. All authors critically reviewed the protocol and the manuscript and gave approval for the publication.

Funding The MILESTONE project was funded by European Commission's 7th Framework Programme under Grant number 602442.

Availability of data and materials The participant consent forms restrict data sharing on a public repository. The MILESTONE consortium invites researchers to contact the corresponding author for requests for statistical code used, instruments used, and anonymised data.

Code availability All analyses were conducted in R. Code can be made available upon request to the corresponding author.

\section{Declarations}

Conflict of interest The MILESTONE project was funded by EU FP7 programme under grant number 602442 . SPS is part-funded by the National Institute for Health Research (NIHR) Collaboration for Leadership in Applied Health Research and Care West Midlands (NIHR CLAHRC WM), now recommissioned as NIHR Applied Research Collaboration West Midlands. The views expressed in this publication are those of the author(s) and not necessarily those of the NIHR or the Department of Health and Social Care. PS is the co-inventor of the HealthTrackerTM and is the Chief Executive Officer and shareholder in HealthTracker Ltd. FF is a Chief Technical Officer and AK is the Chief Finance Officer employed by HealthTracker Ltd, respectively. FCV publishes the Dutch translations of ASEBA, from which he receives remuneration. AM was a speaker and advisor for Neurim, Shire, Infectopharm, and Lilly (all not related to transition research).

Ethics approval The study protocol was approved (ISRCTN83240263; NCT03013595) by the UK National Research Ethics Service Committee West Midlands-South Birmingham (15/WM/0052) and ethics boards in participating countries.

Consent to participate All participants (young people, parents, and clinicians) consented to participating in the MILESTONE study by signing consent forms. Country-specific consent procedures were followed, according to national laws as well as medical ethical committee regulations.

Consent for publication Consent for publication in international peerreviewed journals was incorporated in the study consent forms signed by all participants.

Open Access This article is licensed under a Creative Commons Attribution 4.0 International License, which permits use, sharing, adaptation, distribution and reproduction in any medium or format, as long as you give appropriate credit to the original author(s) and the source, provide a link to the Creative Commons licence, and indicate if changes were made. The images or other third party material in this article are included in the article's Creative Commons licence, unless indicated otherwise in a credit line to the material. If material is not included in the article's Creative Commons licence and your intended use is not permitted by statutory regulation or exceeds the permitted use, you will need to obtain permission directly from the copyright holder. To view a copy of this licence, visit http://creativecommons.org/licenses/by/4.0/.

\section{References}

1. Singh SP (2009) Transition of care from child to adult mental health services: the great divide. Curr Opin Psychiatry 22(4):386-390

2. McGorry PD (2007) The specialist youth mental health model: strengthening the weakest link in the public mental health system. Med J Aust 187(7 Suppl):S53-56

3. Memarzia J, St Clair MC, Owens M, Goodyer IM, Dunn VJ (2015) Adolescents leaving mental health or social care services: predictors of mental health and psychosocial outcomes one year later. BMC Health Serv Res 15:185

4. McNicholas F, Adamson M, McNamara N, Gavin B, Paul M, Ford T, Barry S, Dooley B, Coyne I, Cullen W, Singh SP (2015) Who is in the transition gap? Transition from CAMHS to AMHS in the Republic of Ireland. Ir J Psychol Med 32(1):61-69

5. Islam Z, Ford T, Kramer T, Paul M, Parsons H, Harley K, Weaver T, McLaren S, Singh SP (2016) Mind how you cross the gap! 
Outcomes for young people who failed to make the transition from child to adult services: the TRACK study. BJPsych Bull 40(3):142-148

6. Perera RH, Rogers SL, Edwards S, Hudman P, Malone C (2017) Determinants of transition from child and adolescent to adult mental health services: a Western Australian pilot study. Aust Psychol 52(3):184-190. https://doi.org/10.1111/ap.12192

7. Leavey G, McGrellis S, Forbes T, Thampi A, Davidson G, Rosato M, Bunting B, Divin N, Hughes L, Toal A, Paul M, Singh SP (2019) Improving mental health pathways and care for adolescents in transition to adult services (IMPACT): a retrospective case note review of social and clinical determinants of transition. Soc Psychiatry Psychiatr Epidemiol 54(8):955-963

8. Merrick H, McConachie H, Le Couteur A, Mann K, Parr JR, Pearce MS, Colver A, Transition Collaborative G (2015) Characteristics of young people with long term conditions close to transfer to adult health services. BMC Health Serv Res 15:435

9. Stagi P, Galeotti S, Mimmi S, Starace F, Castagnini AC (2015) Continuity of care from child and adolescent to adult mental health services: evidence from a regional survey in Northern Italy. Eur Child Adolesc Psychiatry 24(12):1535-1541

10. Singh SP, Tuomainen H, Girolamo G, Maras A, Santosh P, McNicholas F, Schulze U, Purper-Ouakil D, Tremmery S, Franic T, Madan J, Paul M, Verhulst FC, Dieleman GC, Warwick J, Wolke D, Street C, Daffern C, Tah P, Griffin J, Canaway A, Signorini G, Gerritsen S, Adams L, O'Hara L, Aslan S, Russet F, Davidovic N, Tuffrey A, Wilson A, Gatherer C, Walker L, Consortium M (2017) Protocol for a cohort study of adolescent mental health service users with a nested cluster randomised controlled trial to assess the clinical and cost-effectiveness of managed transition in improving transitions from child to adult mental health services (the MILESTONE study). BMJ Open 7(10):e016055

11. Gerritsen SE, Maras A, van Bodegom LS, Overbeek MM, Verhulst FC, Wolke D, Appleton R, Bertani A, Cataldo MG, Conti P, Da Fonseca D, Davidović N, Dodig-Ćurković K, Ferrari C, Fiori F, Franić T, Gatherer C, de Girolamo G, Heaney N, Hendrick G, Kolozsvari A, Levi FM, Lievesley K, Madan J, Martinelli O, Mastroianni M, Maurice V, McNicholas F, O’Hara L, Paul M, Purper-Ouakil D, de Roeck V, Russet F, Saam MC, SagarOuriaghli I, Santosh PJ, Sartor A, Schandrin A, Schulze UME, Signorini G, Singh SP, Singh J, Street C, Tah T, Tanase E, Tremmery S, Tuffrey A, Tuomainen H, van Amelsvoort TAMJ, Wilson A, Walker L, Dieleman GC, Consortium M (2021) Cohort profile: demographic and clinical characteristics of the MILESTONE longitudinal cohort of young people approaching the upper age limit of their child mental health care service in Europe. BMJ Open. https://doi.org/10.1136/bmjopen-2021-053373

12. Santosh P, Singh J, Adams L, Mastroianni M, Heaney N, Lievesley K, Sagar-Ouriaghli I, Allibrio G, Appleton R, Davidović N, de Girolamo G, Dieleman G, Dodig-Ćurković K, Franić T, Gatherer C, Gerritsen S, Gheza E, Madan J, Manenti L, Maras A, Margari F, McNicholas F, Pastore A, Paul M, Purper-Ouakil D, Rinaldi F, Sakar V, Schulze U, Signorini G, Street C, Tah P, Tremmery S, Tuffrey A, Tuomainen H, Verhulst F, Warwick J, Wilson A, Wolke D, Fiori F, Singh S (2020) Validation of the transition readiness and appropriateness measure (TRAM) for the managing the link and strengthening transition from child to adult mental healthcare in Europe (MILESTONE) study. BMJ Open 10(6):e033324. https://doi.org/10.1136/bmjopen-2019-033324

13. R Core Team (2020) R: a language and environment for statistical computing. R Foundation for Statistical Computing, Vienna

14. Bates D, Maechler M, Bolker B, Walker S (2015) Fitting linear mixed-effects models using lme4. J Stat Softw 67(1):1-48. https:// doi.org/10.18637/jss.v067.i01

15. van Buuren S, Groothuis-Oudshoorn K (2011) Mice: multivariate imputation by chained equations in R. J Stat Softw 45(3):1-67
16. Robitzsch A, Grund S (2020) miceadds: Some Additional Multiple Imputation Functions, Especially for 'mice'

17. Singh SP, Paul M, Ford T, Kramer T, Weaver T, McLaren S, Hovish K, Islam Z, Belling R, White S (2010) Process, outcome and experience of transition from child to adult mental healthcare. Br J Psychiatry 197:305-312. https://doi.org/10.1192/bjp.bp.109. 075135

18. Steele EH, McKinney C (2020) Relationships among emerging adult psychological problems, maltreatment, and parental psychopathology: moderation by parent-child relationship quality. Fam Process 59(1):257-272. https://doi.org/10.1111/famp.12407

19. IVeldman K, Reijneveld SA, Ortiz JA, Verhulst FC, Bültmann U, (2015) Mental health trajectories from childhood to young adulthood affect the educational and employment status of young adults: results from the TRAILS study. J Epidemiol Community Health 69(6):588-593. https://doi.org/10.1136/jech-2014-204421

20. Gutiérrez-García RA, Benjet C, Borges G, Méndez Ríos E, Medina-Mora ME (2017) NEET adolescents grown up: eightyear longitudinal follow-up of education, employment and mental health from adolescence to early adulthood in Mexico City. Eur Child Adolesc Psychiatry 26(12):1459-1469. https://doi.org/10. 1007/s00787-017-1004-0

21. Wilson A, Tuffrey A, McKenzie C, Street C (2015) After the flood: young people's perspectives on transition. Lancet Psychiatry 2(5):376-378

22. Cleverley K, Rowland E, Bennett K, Jeffs L, Gore D (2020) Identifying core components and indicators of successful transitions from child to adult mental health services: a scoping review. Eur Child Adolesc Psychiatry 29(2):107-121. https://doi.org/10.1007/ s00787-018-1213-1

23. Rimvall MK, van Os J, Rask CU, Olsen EM, Skovgaard AM, Clemmensen L, Larsen JT, Verhulst F, Jeppesen P (2020) Psychotic experiences from preadolescence to adolescence: when should we be worried about adolescent risk behaviors? Eur Child Adolesc Psychiatry 29(9):1251-1264. https://doi.org/10.1007/ s00787-019-01439-w

24. Mulvale GM, Nguyen TD, Miatello AM, Embrett MG, Wakefield PA, Randall GE (2019) Lost in transition or translation? Care philosophies and transitions between child and youth and adult mental health services: a systematic review. J Ment Health 28(4):379-388

25. Belling R, McLaren S, Paul M, Ford T, Kramer T, Weaver T, Hovish K, Islam Z, White S, Singh SP (2014) The effect of organisational resources and eligibility issues on transition from child and adolescent to adult mental health services. J Health Serv Res Policy 19:169-176

26. Appleton R, Elahi F, Tuomainen H, Canaway A, Singh SP (2020) "I'm just a long history of people rejecting referrals" experiences of young people who fell through the gap between child and adult mental health services. Eur Child Adolesc Psychiatry. https://doi. org/10.1007/s00787-020-01526-3

27. Huisman M, Oldehinkel AJ, de Winter A, Minderaa RB, de Bildt A, Huizink AC, Verhulst FC, Ormel J (2008) Cohort profile: the Dutch 'TRacking adolescents' individual lives' survey'. TRAILS Int J Epidemiol 37(6):1227-1235. https://doi.org/10.1093/ije/ dym 273

28. Purcell R, Jorm AF, Hickie IB, Yung AR, Pantelis C, Amminger GP, Glozier N, Killackey E, Phillips LJ, Wood SJ, Harrigan S, Mackinnon A, Scott E, Hermens DF, Guastella AJ, Kenyon A, Mundy L, Nichles A, Scaffidi A, Spiliotacopoulos D, Taylor L, Tong JPY, Wiltink S, Zmicerevska N, McGorry PD (2015) Demographic and clinical characteristics of young people seeking help at youth mental health services: baseline findings of the transitions study. Early Interv Psychiatry 9(6):487-497. https://doi.org/10. 1111/eip. 12133 
29. Grootendorst-van Mil NH, Bouter DC, Hoogendijk WJG, van Jaarsveld S, Tiemeier H, Mulder CL, Roza SJ (2021) The iBerry study: a longitudinal cohort study of adolescents at high risk of psychopathology. Eur J Epidemiol. https://doi.org/10.1007/ s10654-021-00740-w

30. Rothman KJ, Gallacher JE, Hatch EE (2013) Why representativeness should be avoided. Int J Epidemiol 42(4):1012-1014. https:// doi.org/10.1093/ije/dys223

31. Nohr EA, Liew Z (2018) How to investigate and adjust for selection bias in cohort studies. Acta Obstet Gynecol Scand 97(4):407416. https://doi.org/10.1111/aogs.13319

32. Chisholm D, Knapp MR, Knudsen HC, Amaddeo F, Gaite L, van Wijngaarden B (2000) Client Socio-Demographic and Service Receipt Inventory-European Version: development of an instrument for international research. EPSILON Study 5. European Psychiatric Services: inputs linked to outcome domains and needs. $\mathrm{Br}$ J Psychiatry Suppl 39:s28-33

33. Achenbach T, Rescorla L (2001) Manual for the ASEBA Schoolage forms and profiles. University of Vermont, Research Center for Children, Youth, and Families, Burlington

34. Achenbach T, Rescorla L (2003) Manual for the ASEBA adult forms and profiles. University of Vermont, Research Center for Children, Youth, and Families, Burlington

35. Guy W (1976) Clinical global impressions. ECDEU assessment manual for psychopharmacology. US Department of Health Education and Welfare, Rockville

36. Pinna F, Deriu L, Diana E, Perra V, Randaccio RP, Sanna L, Tusconi M, Carpiniello B, Cagliari Recovery Study G (2015)
Clinical Global Impression-severity score as a reliable measure for routine evaluation of remission in schizophrenia and schizoaffective disorders. Ann General Psychiatry 14:6

37. Glazer K, Rootes-Murdy K, Van Wert M, Mondimore F, Zandi P (2018) The utility of PHQ-9 and CGI-S in measurement-based care for predicting suicidal ideation and behaviors. J Affect Disord

38. Gundersen SV, Goodman R, Clemmensen L, Rimvall MK, Munkholm A, Rask CU, Skovgaard AM, Van Os J, Jeppesen P (2019) Concordance of child self-reported psychotic experiences with interview- and observer-based psychotic experiences. Early Intervent Psychiatry 13(3):619-626

39. Rocca P, Galderisi S, Rossi A, Bertolino A, Rucci P, Gibertoni D, Montemagni C, Bellino S, Aguglia E, Amore M, Bellomo A, Biondi M, Carpiniello B, Cuomo A, D'Ambrosio E, dell'Osso L, Girardi P, Marchesi C, Monteleone P, Montemitro C, Oldani L, Pacitti F, Roncone R, Siracusano A, Tenconi E, Vita A, Zeppegno P, Steardo L Jr, Vignapiano A, Maj M, Members of the Italian Network for Research on Psychoses i (2018) Disorganization and real-world functioning in schizophrenia: results from the multicenter study of the Italian Network for Research on Psychoses. Schizophr Res 201:105-112

40. Mucci A, Rucci P, Rocca P, Bucci P, Gibertoni D, Merlotti E, Galderisi S, Maj M, Italian Network for Research on P (2014) The Specific Level of Functioning Scale: construct validity, internal consistency and factor structure in a large Italian sample of people with schizophrenia living in the community. Schizophr Res 159(1):144-150 


\section{Authors and Affiliations}

S. E. Gerritsen ${ }^{1}$ (D) . L. S. van Bodegom ${ }^{1,2} \cdot$ G. C. Dieleman ${ }^{1}$ - M. M. Overbeek ${ }^{2,3} \cdot$ F. C. Verhulst ${ }^{1,4} \cdot$ D. Wolke ${ }^{5}$.

D. Rizopoulos ${ }^{6} \cdot$ R. Appleton ${ }^{7}$.T. A. M. J. van Amelsvoort ${ }^{8,9}$. C. Bodier Rethore ${ }^{10} \cdot$ F. Bonnet-Brilhault ${ }^{10} \cdot$ I. Charvin $^{11}$. D. Da Fonseca ${ }^{11} \cdot$ N. Davidović ${ }^{12,13} \cdot$ K. Dodig-Ćurković ${ }^{14,15,16} \cdot$ A. Ferrari ${ }^{17,18} \cdot$ F. Fiori $^{19,20,21}$ - T. Franić ${ }^{12,13}$.

C. Gatherer ${ }^{22}$ - G. de Girolamo ${ }^{17}$ - N. Heaney ${ }^{19}$ - G. Hendrickx ${ }^{23} \cdot$ R. Jardri ${ }^{24} \cdot$ A. Kolozsvari ${ }^{21} \cdot$ H. Lida-Pulik ${ }^{25}$. K. Lievesley ${ }^{19} \cdot$ J. Madan ${ }^{26} \cdot$ M. Mastroianni ${ }^{19,20} \cdot$ V. Maurice ${ }^{27} \cdot$ F. McNicholas ${ }^{28,29} \cdot$ R. Nacinovich ${ }^{30,31} \cdot$ A. Parenti ${ }^{32}$. M. Paul ${ }^{22,33} \cdot$ D. Purper-Ouakil ${ }^{27,34} \cdot$ L. Rivolta ${ }^{35,36} \cdot$ V. de Roeck R7,38 $^{37}$. Russet ${ }^{27} \cdot$ M. C. Saam $^{39} \cdot$ I. Sagar-Ouriaghli $^{19}$. P. J. Santosh ${ }^{19,20,21}$ - A. Sartor ${ }^{40}$ - U. M. E. Schulze ${ }^{39} \cdot$ P. Scocco ${ }^{41,42}$. G. Signorini ${ }^{17}$. S. P. Singh ${ }^{22}$. J. Singh ${ }^{19,20}$.

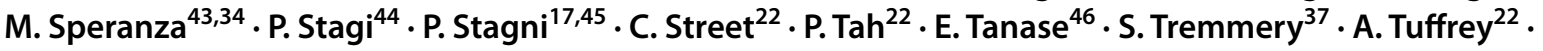
H. Tuomainen ${ }^{22} \cdot$ L. Walker ${ }^{22} \cdot$ A. Wilson ${ }^{22} \cdot$ A. Maras ${ }^{1,2} \cdot$ for the Milestone Consortium

1 Department of Child and Adolescent Psychiatry and Psychology, Erasmus Medical Center, P.O. Box 2060, 3000 CB Rotterdam, The Netherlands

2 Yulius Academy, Yulius Mental Health Organization, Dordrecht, The Netherlands

3 Clinical Child and Family Studies, Vrije Universiteit Amsterdam, Amsterdam, The Netherlands

4 Department of Clinical Medicine, University of Copenhagen, Copenhagen, Denmark

5 Department of Psychology, University of Warwick, Coventry, UK

6 Department of Biostatistics, Erasmus Medical Center, Rotterdam, The Netherlands

7 NIHR Mental Health Policy Research Unit, Division of Psychiatry, University College London, London, UK

8 Department of Psychiatry and Neuropsychology, University of Maastricht, Maastricht, The Netherlands

9 Mondriaan Mental Health Care, Heerlen, The Netherlands

Hospitalier Universitaire de Marseille, Marseille, France IRCCS Istituto Centro San Giovanni di Dio Fatebenefratelli, Brescia, Italy

18 DISM, ULSS 16, SOPROXI Onlus, Padua, Italy

19 Department of Child and Adolescent Psychiatry, Institute of Psychiatry, Psychology and Neuroscience, Kings College London, London, UK

20 Centre for Interventional Paediatric Psychopharmacology and Rare Diseases, South London and Maudsley NHS Foundation Trust, London, UK

21 HealthTracker Ltd, Kent, UK

22 Warwick Medical School, University of Warwick, Coventry, UK
23 Department of Neurosciences, Centre for Clinical Psychiatry, KU Leuven, Leuven, Belgium

24 Lille Neurosciences and Cognitions, Plasticity and Subjectivity Team, CURE Platform, Université de Lille, INSERM (U-1172), Fontan Hospital, CHU Lille, Lille, France

$25 \mathrm{CH}$ Versailles, Versailles, France

26 Warwick Clinical Trials Unit, Warwick Medical School, University of Warwick, Coventry, UK

27 Centre Hospitalier Universitaire de Montpellier, Saint Eloi Hospital, Montpellier, France

28 School of Medicine \& Medical Science, University College Dublin, Dublin, Republic of Ireland

29 Lucena CAMHS, SJOG, Dublin, Republic of Ireland

30 Child and Adolescent Neuropsychiatry Unit, ASST Monza, Monza, Italy

31 Università Degli Studi Milano Bicocca, Milan, Italy

32 Centre Hospitalier Universitaire de Lille, Lille, France

33 Coventry and Warwickshire Partnership NHS Trust, Coventry, UK

34 INSERM, CESP U1018, PsyDev, University Paris Saclay, UVSQ, Versailles, France

35 Psychiatric Epidemiology and Evaluation Unit, Saint John of God Clinical Research Center, Brescia, Italy

36 Department of Mental Health, Psychiatry Unit, San Gerardo Hospital, Monza, Monza Brianza, Italy

37 Department of Neurosciences, KU Leuven, Leuven, Belgium

38 Child and Youth Studies, Campus Social School, University Colleges Leuven Limburg, Heverlee, Belgium

39 Department of Child and Adolescent Psychiatry/Psychotherapy, University of Ulm, Ulm, Germany

40 Josefinum Augsburg, Klinik für Kinder- und Jugenspsychiatrie und Psychotherapie, Augsburg, Germany

41 Department of Mental Health, ULSS 6 Euganea, Padua, Italy

42 SOPROXI Onlus, Padua, Italy

43 Service Universitaire de Psychiatrie de l'Enfant et de l'Adolescent, Centre Hospitalier de Versailles, Versailles, France 
44 Child and Adolescent Neuropsychiatry Unit, AUSL Modena, Modena, Italy

45 Child and Adolescent Neuropsychiatry, Department of Mental Health, Modena, Italy
46 Abteilung für Psychiatrie und Psychotherapie des Kindes-und Jugendalters Weissenau, ZfP Südwürttemberg, Ravensburg, Germany 